ON THE INTIMATE

\title{
STRUCTURE OF THE HUMAN KIDNEY,
}

\author{
AND ON THE \\ CHANGES WHICH ITS SEVERAL COMPONENT PARTS UNDERGO IN \\ “BRIGHT'S DISEASE.”*
}

BY JOSEPH TOYNBEE, F.R.S.,

ONE OF THE SURGEONS TO THE ST. GEORGE'S AND ST. JAMES'S

GENERAL DISPENSARY.

Received April 24th-Read June 23rd, 1846.

Perhaps no one disease has, during the last twenty years, excited a greater share of attention, or enlisted, in its elucidation, a larger amount of professional skill, than that renal affection which is characterized by a secretion of albuminous urine, and commonly known as "Bright's disease."

Two circumstances sufficiently explain the importance at-

- Previous to entering upon the subject of this paper, it may be permitted me to say a few words respecting the joint labours of Dr. Bright and myself. In the year 1838, having minutely injected a specimen of granular kidney, I perceived that the blood-vessels of the Malpighian tuft were considerably enlarged, and communicated that fact at a meeting of the Westminster Medical Society. Towards the latter end of 1839, I showed Dr. Bright several additional specimens which $I$ had succeeded in preparing in illustration of this view, and received from him a promise of opportunities for further experiment. Accordingly, in the course of 1840, Dr. Bright sent me specimens, accompanied with notes; and during that and the three following years we procured and injected nearly one hundred kidneys, submitting portions of each to microscopic investigation, and carefully noting every matter which seemed of any importance. These preparations are 
tached to the investigation; these are the extreme frequency and fatal character of the disease, and the difficulties which attend a satisfactory elucidation of its true nature. This being the case, every attempt which promises to throw any additional light upon the peculiarities of the affection, will, doubtless, be received with satisfaction; in this hope, the following observations are offered.

\section{Of the Anatomy of the Kidney.}

1. The Parenchyma.-To those who have paid attention to the intimate structure of glands, it is well known that, besides the blood-vessels, ducts, tubuli, and nerves, there are intervascular spaces of no inconsiderable size, which are occupied by a substance that has received the name of Parenchyma. Malpighi, in whose writings, as Professor Owen has truly said, the germs may be found of many of the recent discoveries in physiology, undertook numerous researches into the nature of the parenchyma.

Subsequent to Malpighi, anatomists, misled by the indefinite and unphilosophical writings of Ruysch, appear to have entertained very vague notions of the nature of the parenchyma of glands, and to have regarded it as a mere cellular network connecting together the vessels of an organ; nor do they appear to have suspected that it had any other function to perform. The modern researches of Schleiden, Schwann, and Henle, clearly show that the parenchyma con-

now in my possession. In the year 1841, at Dr. Bright's expense, a series of drawings and engravings was made in illustration of the subject, and of the views to which our investigations had led. Subsequently to this period, various circumstances arose to prevent the issue of a work which had been designed to comprise the results of our joint labours; and I am now indebted to the kind liberality of Dr. Bright for the opportunity of using the illustrations to which I have alluded, and which form a large share of the series accompanying this paper. So sensible, indeed, am I that nearly everything of value which may be contained in the observations which follow, is to be attributed to the assistance of Dr. Bright, that it is not without some degree of diffidence that I venture to prefix my name alone to the present communication. 
sists of cells and corpuscles; and recent investigations tend to establish the extreme importance of these cells in the processes of development, nutrition, and secretion. It has been demonstrated by myself that they almost wholly compose those tissues which, in a healthy state, contain no blood-vessels, and in various forms enter into the structure of animal solids.*

By many modern anatomists the parenchyma of glands has been comparatively neglected. Too exclusive an attention has been directed to the epithelial cells lining the walls of the excretory ducts, to which the office of eliminating from the blood the matter to be secreted has been assigned. It should, however, be remembered that many of the bloodvessels of glands, instead of ramifying over the surface of the excretory tubes, are distributed through the parenchyma of the organ, where there is every reason to believe that the blood contained in them is acted upon by the parenchymal cells,which are known to possess an active function, - being thereby at least prepared for that further change which takes place during its elimination, by the agency of the epithelial cells, in its passage into the interior of the excretory duct.

The relation in which the parenchymal cells stand to the nervous system is a subject of great interest. After numerous dissections which $I$ have made for the purpose of ascertaining the way in which the nervous filaments terminate in the kidney, the only conclusion to which I could arrive is, that the filaments end by becoming continuous with the parenchyma of the organ, precisely in the same way as $I$ have observed those in the tail of a tadpole to become directly continuous with the radiating fibres of stellated corpuscles, and the filaments from the corpuscles to communicate with each other.

When the practitioner observes that a total suppression of urinary secretion follows an injury of that part of the spinal cord from which the kidney appears to derive a portion of its

- Researches tending to prove the Non-Vascularity and uniform mode of Organization and Nutrition of certain Animal Tissues. Philosophical Transactions, Part II. 1841.

voL. $\mathbf{x x I X}$. 
nervous power, and bears in mind that certain mental impressions can cause an almost instantaneous formation of other secretions in large quantities, as in the sudden flow of tears or saliva, he can scarcely doubt that every part of these glands is under the immediate influence of the nervous system. Should he proceed to examine the writings of anatomists with the view of understanding the distribution of the nerves through the glands, the only information that will be found is, that the nervous filaments have been traced along the trunks of the larger vessels at their entrance into the organ. I have, however, succeeded in tracing those filaments completely into the substance of a gland, where they accompany the arteries, and, as I have stated, where their extremely minute filamentary radiations have appeared to become continuous with the parenchyma of the organ.

In connection with the above, I am desirous of adding another observation. It has been stated that the parenchyma of glands is composed of corpuscles or cells to which important functions have been assigned. Cells of a character not very dissimilar are seen lining the interior of the tubuli as well as the blood-vessels. So abundant are they in the tubuli as to occupy frequently no inconsiderable share of the internal space; and they might with propriety be denominated intra-tubular cells, to distinguish them from the others, which might be termed the parenchymatous or inter-tubular cells. In the testicle, the latter description of cells are but very sparingly diffused, being principally found in contact with the blood-vessels, and between them and the tubuli seminiferi; while the former, or those within the tubuli, are, on the contrary, very numerous, and so loosely connected that gentle pressure easily causes separation.

\section{The Tubuli Uriniferi.}

The course of the tubuli uriniferi through the central and cortical divisions of the kidney, and their presence even on its surface, were illustrated by Hunter in some injected sections of the kidney of the horse, which are preserved in the 
Physiological Gallery of the Museum of the College of Surgeons in London.

Since those preparations were made, several anatomists have succeeded in injecting the tubuli uriniferi of the lower animals. Müller has distended them as far as the surface of the kidney of the horse, in which he says "they anastomose freely." According to Krause, "the urinary canals anastomose with each other, and also terminate by free cæcal extremities, just as is the case with the convoluted tubuli seminiferi."* In the Hunterian Museum may be seen a section of the entire kidney of a rhinoceros, in which I was enabled to inject the tubuli so as to display them in their course throughout the entire organ. $\dagger$

More recently, Mr. Bowman's excellent paper on the kidney has appeared; and as it refers especially to the anatomical details involved in the present communication, I shall refer occasionally to his opinions in the course of my observations.

To obtain a satisfactory examination of the tubuli uriniferi, it is absolutely necessary that they should be viewed in a distended state, produced not merely by injection of the arterial system, but by a conjoint injection via the ureter. Subsequent to my injection of the kidney of the rhinoceros, in which the tubuli were filled to the surface of the organ, I have succeeded to the same extent with the human kidney in twenty instances out of one hundred and seventeen specimens which were the subject of careful experiments. It is from an attentive study of these injections that the descriptions which follow have been derived.

Near the apices of the mammillary processes, the tubuli uriniferi are so densely packed together, as to present an appearance of contact; all that intervenes being a small quantity of the parenchymatous tissue, and a few bloodvessels. They may be said to form, at this point, one bundle of tubes. Towards the base of the pyramidal masses, how-

- Müller's Physiology, p. 453, vol. 1.

+ Physiological Gallery. In this specimen the arteries are filled with a red-coloured injection, and the tubuli with a white. 
ever, this tubular fasciculus divides into a series of smaller ones, separated from each other by coniform masses of bloodvessels, prolonged from the cortex towards which their bases are directed.-(Plate VII. fig. 2.)

All the tubuli lying between the apex and base of the pyramidal mass are very uniform in their dimensions; and though not a few of them, in their course through this portion of the kidney, are bifurcated, yet each branch remains nearly as capacious as the original tube.

Of the tubuli in the cortex. - Immediately on entering the cortical coat, the tubular fasciculi just described, resolve into their component tubes, which thence disperse themselves through every part of the vascular tissue; some taking the direction of the external surface, and others that of the interpyramidal spaces. The mode in which the tubuli are distributed in the cortical substance is rather complicated, abounding in tortuosities, plexuses, convolutions, and dilatations, the latter not unfrequently of considerable size. Occasionally a tube, after emerging from the pyramidal mass, makes an abrupt turn, pursues a retrograde course for some distance, and then resumes its original direction. Others proceed towards the surface of the organ, giving out branches by the way, which are often of co-equal capacity with themselves. The nearer they approach to the surface, the more numerous become the ramifications of the tubes, which are not merely continuous with each other, but with those arising from the adjacent tubuli, with which they interweave, and form plexuses. In addition to the plexuses, the tubuli in the cortex exhibit convoluted masses, and at intervals distinct dilatations and loops. A tube, for instance, will divide as it emerges from the pyramidal mass, and with one of its divisions form a loop with a similar branch from a neighbouring tube. Another tube will separate into two branches, which after running for a short distance, reunite. From the circle thus formed, in other cases, a tube will be given off, from which, at a short distance, another will spring, and form a similar loop.-(Plate VII. figs. 1 to 11.) 


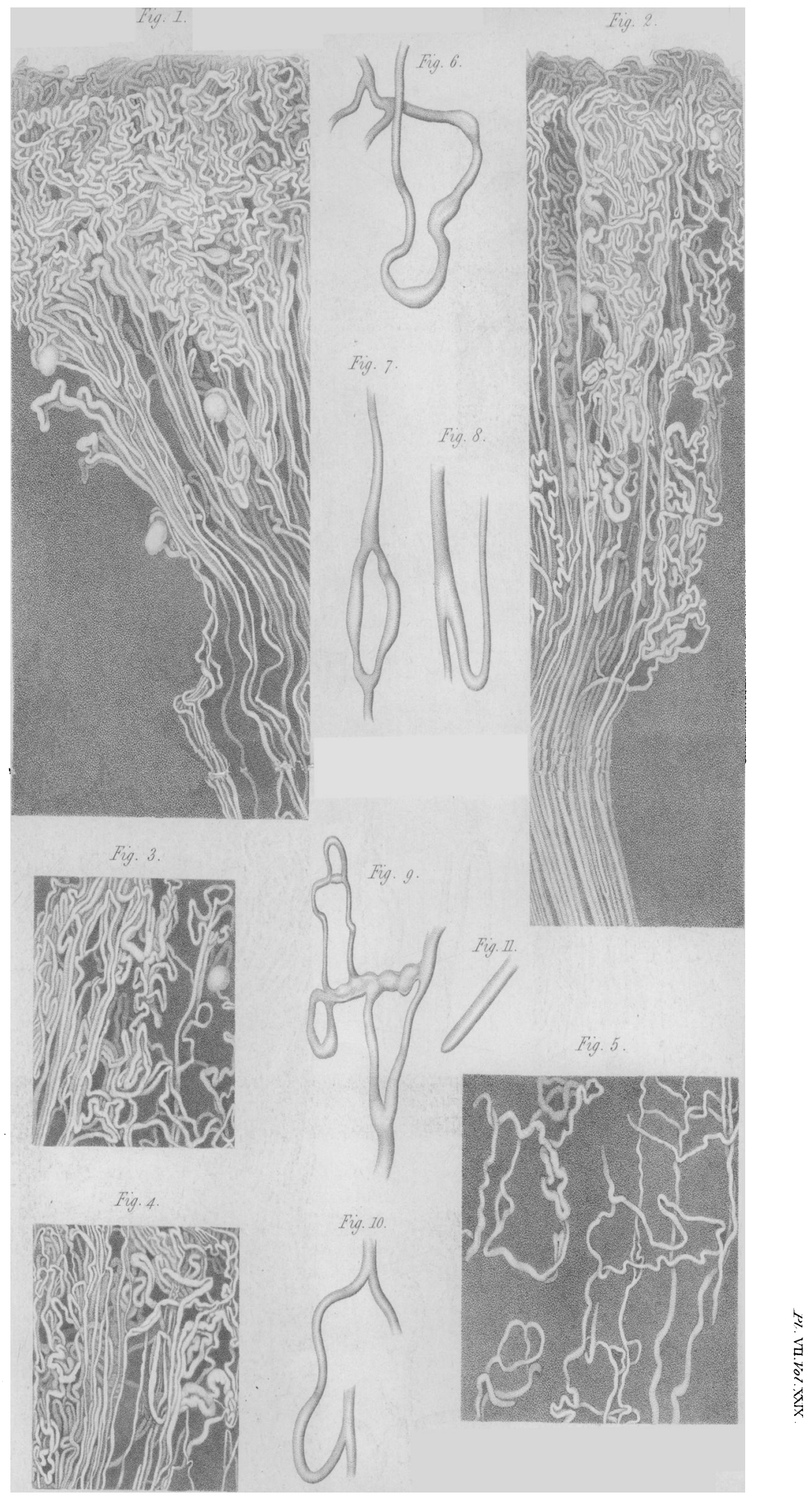




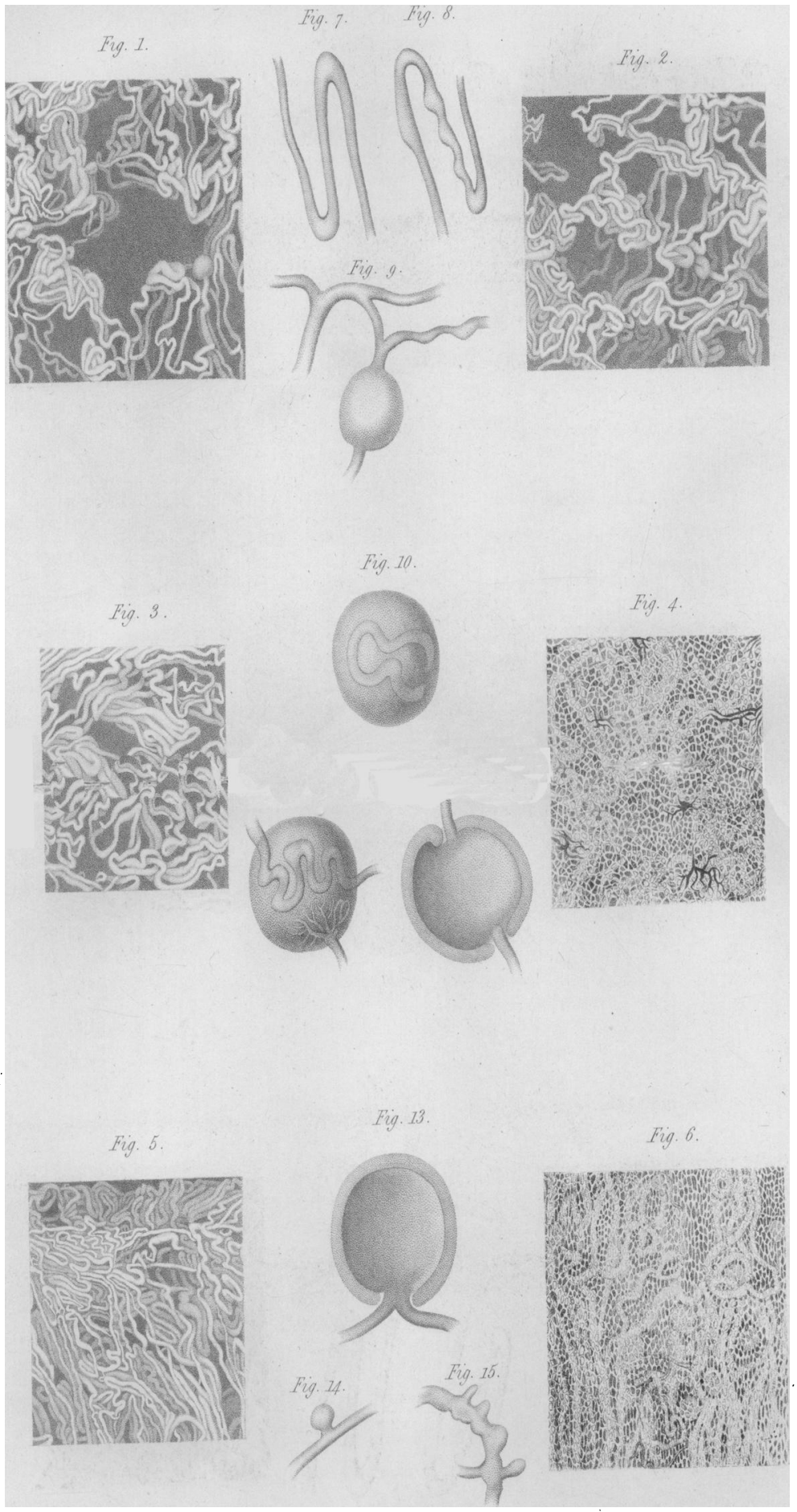


The tubuli in the cortical part of the kidney also terminate in the corpora Malpighiana,-a fact which Shumslansky was the first to describe; but of which Mr. Bowman has given a more accurate account. The relations of the tubuli with the corpora Malpighiana will presently come under consideration.

Of the tubuli on the surface of the kidney.-The surface of the organ exhibits a more regular arrangement of the tubuli than is perceptible in the interior. There is a general disposition to form masses, or bundles, the component tubuli of which often appear to be in absolute contact. A connection is also established between the principal masses by the prolongation of one or more tubuli. The spaces arising from these intersections are tolerably well defined, though their dimensions are not uniform. A kidney, therefore, of which the tubuli have been successfully injected, will present, with the intervening depressions, a lobular external appearance, not unlike what is visible to the naked eye even in the uninjected specimen. Loops, convolutions, and dilatations, freely intercommunicating, characterize the tubuli of the surface. A small branch of a tube will, in one place, enter at right angles the convolutions of its neighbour; in another, a tube will be found to divide and subdivide, and finally re-unite, either in one trunk or in two, which take opposite courses, and communicate with separate tubuli. Here, a tube will suddenly swell into a convoluted mass; there, it will be subject to gradual dilatation, and as gradually regain its primitive dimensions. So numerous, indeed, are the variations in the distribution of the exterior tubuli, that the mode in which they are disposed can only be understood by referring to specimens, or to the engravings.-(Plate VIII. figs. 1, 2, 3, and 5.)

Of the manner in which the tubuli uriniferi terminate.It has been stated already, that one way in which the tubuli uriniferi terminate, is by communicating with each other. Mr. Bowman, however, entertains a different opinion on this subject. He says, "Some distinguished anatomists have held that the tubes end in a plexiform manner, and have 
stated themselves unequivocally to have seen this arrangement in injected specimens. I am induced to believe this opinion founded on deceptive appearances, either such as that abovementioned, or that occasioned by the overlapping of the injected tubes. Others have considered the tubes to terminate in free blind extremities, unconnected with the Malpighian bodies." * As will afterwards be seen, the true cause of Mr. Bowman's disbelief of the opinion first stated, will be found in the fact of the probable incompleteness of his own injections.

A second mode in which the tubuli terminate, is in the corpora Malpighiana. Shumslansky first advanced this view, and Mr. Bowman has pointed out what he considers to be the true relations, from his examination of injected specimens. The ground on which I rest my impression that a communication exists between the Malpighian corpuscles and the tubuli, is that of having succeeded in distending the capsules of the corpora from the tubuli without any extravasation into the vascular tissues. It is singular that Mr. Bowman should not only deny the possibility of injecting the capsules of the corpora Malpighiana from the tubuli, but actually head a section of his paper, "By the tubes the corpora Malpighiana cannot be injected." "Many anatomists," he states, "have taken extreme pains to inject the tubes from the pelvis of the kidney by means of the air-pump ; but never has a single Malpighian body been thus filled. This, as it has been said, is a conclusive proof that the Malpighian bodies are not placed at the extremities of the tubes." Having thus assumed the impossibility of injecting the corpora Malpighiana from the tubuli, Mr. Bowman proceeds to demonstrate at some length that this "is a necessary effect of the anatomical disposition of parts." It is not my intention to criticize the grounds assigned by Mr. Bowman to account for the impossibility of injection, its possibility being abundantly manifest in many of my own specimens, in which those bodies are in this way distended; but the circum-

* Philosophical Transactions, Part 1, 1842. 
stances will excuse the observation, that while in scientific investigations we ought never to take for granted what has not been proved, it is equally incumbent on us not to deny the possibility of anything, merely because we may have been unable to arrive at its demonstration.

Although there is no doubt that the uriniferous tubuli have communication with the corpora Malpighiana, the precise nature of the communication has, it appears to me, not yet been satisfactorily stated. The view adopted by Mr. Bowman is, that the tubuli have an expanded origin, similar to that of the urethra in its origin from the bladder; that this expansion is composed of the basement membrane of the tube, aud encloses in it the rounded tufts of capillary vessels, usually designated the corpora Malpighiana. By this mode of arrangement, the capillary vessels are in the cavity of the excretory tube, in direct contact with the urine, and unprotected by epithelium, mucus, or any kind of membrane.

The true relation of the tubuli to the corpora Malpighiana would seem to be as follows :-

1st. The capsule of the corpus Malpighianum, instead of being, as supposed, an expansion of the tubule, is a distinct globular investment, enveloping both the tubule and the tuft of vessels.

2nd. This globular investment is neither continuous with the tubule, nor with the blood-vessels, but is expanded over them.

3rd. Into one part of the capsule the artery enters, while the other receives the tubule.

4th. The artery divides and subdivides, so as to form a globular mass of capillaries in the interior of the capsule from which the efferent vessel emerges.

5 th. The tubule, after penetrating the capsule, becomes tortuous, and twists into a coil, and after being in contact with the ramifications of the corpus, it emerges from the capsule.* -(See Plate VII. figs. 1, 2, and 3; and Plate VIII. figs. 9, $10,11,12$, and 13.)

* Since writing the above observations, I have read, in the Medical Times, 


\section{Of the Arteries of the Kidney.}

The principal mode of termination of the renal arteries is in the corpora Malpighiana, although I am not prepared to deny that some of the branches may form a capillary network without entering the corpus. The structure and relations of the corpora Malpighiana are deserving of the most attentive consideration.

The corpora Malpighiana.-From the time of their discoverer to the present day, these bodies appear to have been objects of careful examination to various anatomists, among whom, notwithstanding, serious difference of opinion prevailed as to their structure and functions. Those modern investigators, however, who have submitted successful injections of the corpora Malpighiana to inspection by the microscope, seem to agree that they consist of plexuses formed by ramifications from the arterial branches. Müller, who is of this opinion, describes them as lying " in vesicular cavities of the cellular tissue between the tubuli uriniferi." Huschke also, after delineating the Malpighian body in the kidney of the salamander, characterizes it as made up of the convolutions of a single blood-vessel. Berres has contributed very beautiful drawings of the injected corpuscles in the human subject, and demonstrated that they consist of the divisions and subdivisions of a small artery, that their form is usually circular, and that small vessels are given off from their circumference.

an extract from a paper on this subject by Dr. Gerlach, of Mayence. He states that he has also succeeded in injecting the tubuli uriniferi from the ureter, and the Malpighian capsules at the same time. He states, however, "that the capsules do not form the extremities of the uriniferous tubes, as $\mathrm{Mr}$. Bowman supposes, but constitute only diverticula, which communicate by a small neck with the angle formed by the uriniferous tubes, winding through the cortical part of the kidneys." Another important point noticed by Dr. Gerlach is, that he found the Malpighian bodies (the tufts) in the capsules covered with a layer of cells, which are in continuation with the cellules lining the internal surface of the capsules in a manner analogous to that in which the peritoneum is reflected on the intestines from the internal surface of the abdomen. In frogs, this membrane lining the capsule is covered with ciliæ. 
The corpora Malpighiana are only to be found in the cortical portion of the kidney, where, though they may seem at first view to be promiscuously distributed to all parts alike, yet a closer inspection will discover that they are ranged more or less in rows radiating from the centre towards the surface of the organ, which rows correspond with the interspaces of the columns of tubuli in the central part.

Of the structure of the corpora Malpighiana.-These bodies are composed of two distinct elements,-a plexus of bloodvessels and a membranous capsule, which completely surrounds and envelops the plexus. Some of the most marked and frequently-occurring features of the disease treated of in the second part of these researches, will be found to arise from a morbid condition of these two elements of the corpora.

Of the capsules.-If a section be made of a healthy uninjected kidney, the naked eye is able to detect the presence, over the whole surface, of numerous globular vesicles, whose colour is a shade deeper than the surrounding parts. Several of these vesicles will be found to have been partially dislodged, from the substance of the organ, in making the section, and to project from its surface, while corresponding cavities will indicate where others have been dislodged during the same operation. The round bodies when viewed through the microscope, are discovered to consist of a thin transparent membrane enclosing convolutions of blood-vessels. This membrane is disposed in a spherical arrangement, and gives to the corpus Malpighianum its globular form. These bodies become flattened by a gentle compression, but resume their spheroidal figure as soon as the pressure is removed. The membrane just mentioned may be appropriately termed the capsule of the corpus Malpighianum. It is thin and transparent, nor can the microscope detect in it either fibres or cells. To its internal surface numerous fine granules are attached, and from one part of its circumference there frequently extends a funnel-shaped prolongation, which is in fact the point from whence the uriniferous tubule emerges. The mode of con- 
nection between the two has been already treated of. By lacerating this capule it can be readily separated from the vessels it contains, which are attached to its surface only at one point, being elsewhere surrounded by a small quantity of fluid. The external surface of the capsule itself is also but slightly attached to the parenchyma of the organ, from which it may be detached with the greatest ease.

The contents of the capsule consist of convolutions of vessels closely aggregated together, and apparently attached to a central vessel from which they radiate. Towards their circumference the convolutions present dilatations, the greater number of which do not appear to be continuous with any other vessels. The exact mode in which the blood-vessels of the Malpighian body are disposed, can only be thoroughly understood by a careful examination of properly-prepared specimens. It will be seen that the small artery of the corpus has various modes of distribution. In some instances, immediately on entering the capsule it divides into two or three branches, these again subdivide and form the convoluted plexus, which plexus having been again collected into a single trunk, issues from the capsule close to the point at which the artery entered it, and then divides once more to form the capillaries of the organ. From the minuteness of the healthy corpus, it is impossible from that to ascertain with precision the manner in which the emerging vessel of the corpus takes its rise from the rete; but from an examination of the Malpighian bodies when morbidly enlarged, it would appear that it springs from the convoluted vessels by radicles of much smaller dimension than the convolutions themselves.(Plate IX. figs. 1 and 2.) In some instances the rete seems formed by a single branch of a single vessel in which the artery terminates. Though as a general rule it is otherwise, I have occasionally been enabled to obtain a distinct view of the capillaries arising directly from the convolutions of the corpus. The single trunk which emerges from the corpus sometimes unites with another proceeding from an arterial branch which is entirely unconnected with the corpora. In 
Fig. 1

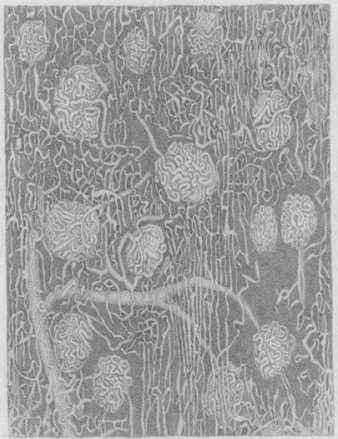

Fig. 3.

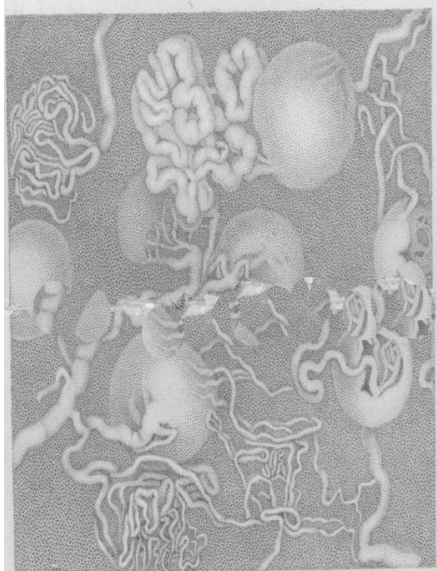

Fig. 5.

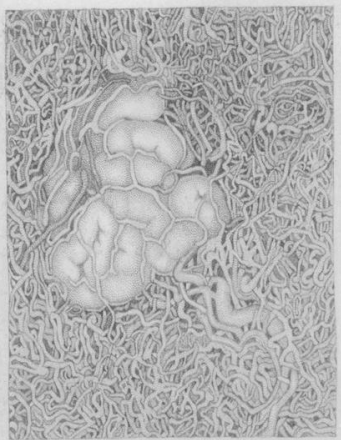

Fig. 2

Propy y.

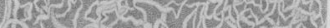

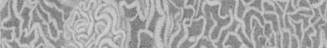

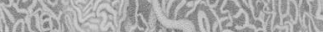

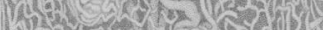

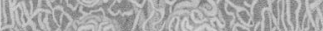

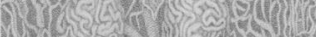

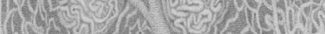

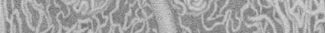

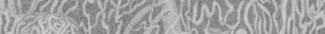

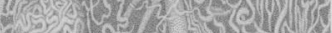

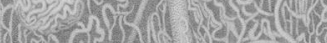

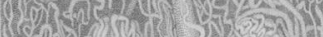
*7. (5)

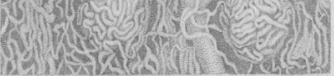

Fig. 4 .

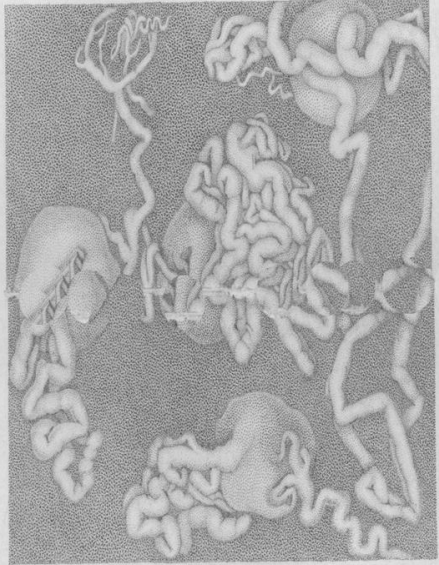

Fig. 6 .

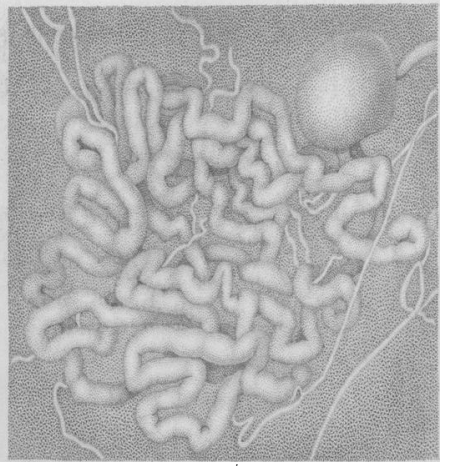

$\frac{\sqrt{x}}{x}$ 
this case, the combined trunk immediately divides again into capillaries. There occur instances where the efferent vessel emerges from a part of the capsule distant from that at which the efferent vessel entered. The meshes of the capillaries are elongated in a direction from the centre to the surface of the organ : and it has been already noted that the Malpighian bodies are disposed in a more or less regular and lineal order, the tendency of the lines being from the tubular portion of the organ towards its surface. The spaces between these rows contain the capillary ramifications, and correspond with the columns of tubuli in the tubular division, in the like manner as the rows of corpora do with the interspaces of the columns.-(Plate VIII. figs. 4 and 6.) The arteries in the tubular region of the kidney present the peculiarity of following a straight course, and are arranged in bundles of the shape of elongated cones whose bases are continuous with the cortical portion, and their apices directed towards the mammillary processes.

\section{The Veins of the Kidney.}

Like the arteries of the kidney, the veins are also remarkable for their large dimensions. The trunks have their commencement on the surface of the organ, in small stellated branches, which, passing through the cortex, are there considerably increased in volume by the junction of the numerous ramifications at the bases of the pyramidal masses. The veins situated in the tubular region having entered them, they, by their union, form the larger vessels which surround the pelvis, and terminate at length in the renal vein. The peculiar disposition of the veins is the efficient cause of that lobulated appearance of the surface of the kidney which has been described by various anatomists, and, among others, by Ferrein.*

It is not a little remarkable, however, that entertaining these views, Ferrein should have caused the kidney to be engraved as though it were composed of numerous pyramids, having their apices in the tubular region, and their bases re-

* Mémoires de l'Académie Royale des Sciences, 1794, pp. 501, 502. 
presented by the angular intersections of the surface of the organ. In the uninjected section these pyramids are figured as if throughout they remained perfectly distinct.

The researches which I have conducted, afford abundant evidence that the substance of the kidney is not divided into pyramids, and that the appearances delineated by M. Ferrein as existing not merely on the surface but in the substance of the organ, are caused by the local arrangement of the bloodvessels. The peculiar lobular phase of the exterior surface is, in fact, the natural result of the mode in which the small veins are disposed. Instead, therefore, of the interspaces "being in some places marked by the ramifications of a vein," it will be found that it is the venal ramifications which really produce all the singular angular intersections characteristic of the superficies; and that, whenever there is a deficiency of blood in the veins, the phenomena cease to be perceptible.

If a section of the surface of the kidney, with the veins and capillaries well distended, be microscopically examined, the veins will appear so disposed as to form the boundaries of various interspaces whose configuration is mostly either pentangular or hexagonal.

These spaces impart the lobulated appearance to the surface of the organ, and within them the capillaries ramify, (Plate X. fig. 1,) forming a very intricate plexus, and giving rise to the white hue generally observable. The capillaries are continuous with the circumscribing veins; and, as they are usually empty, or contain but a very trifling quantity of blood, they appear by contrast paler than the latter. The degree to which the veins are distended in different specimens, and even in parts of the same specimen, being extremely variable, a corresponding diversity in the apparent forms of the lobuli, or interspaces, is the natural result. In some parts, for instance, the veins are completely charged, and the terminal lines of the spaces consequently perfect (Plate X. fig. 1. portion not magnified) ; in others, the veins being only partially filled, there is less distinctness in the lobular outline. Thevarying extent, therefore, to which the blood-vessels may be distend- 
Fig. 1

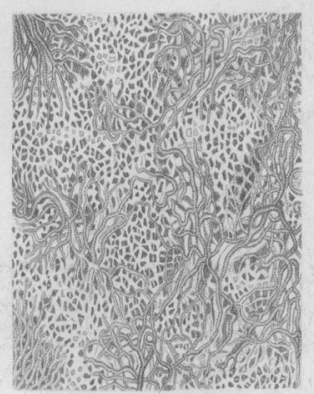

Fig. 3.

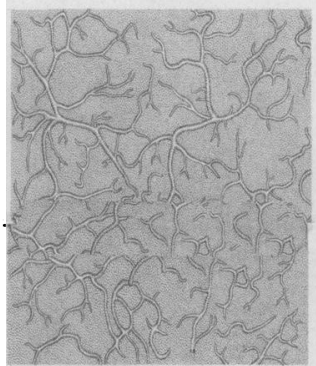

Fig. 2.
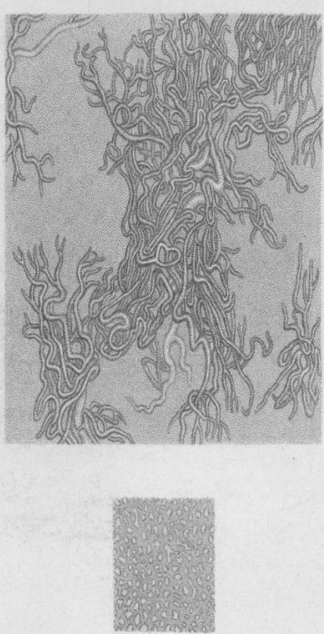

Fig. 4.
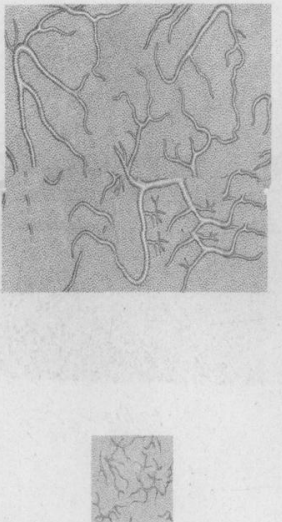

Fig. 5.

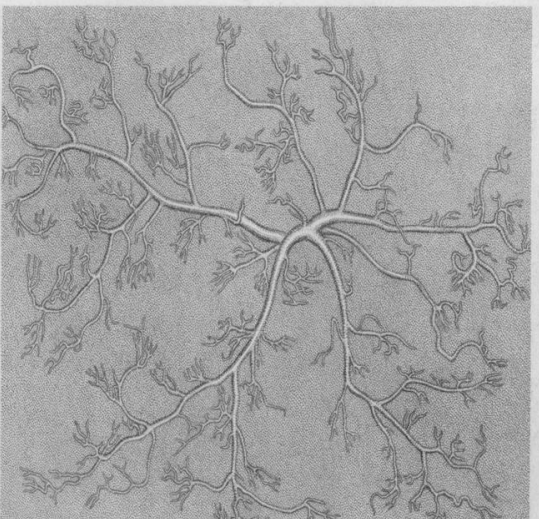


ed, produces as marked a difference in the appearance of the surface of the kidney, as arises in the liver from an analogous cause.* It will be observed, that at some points the lines thicken, and this occurs wherever two or more veins meet at one angle $\mathrm{V}$; the phenomena resulting from the junction of the veins at the spot. The thickened portion is, in fact, the commencement of the trunk of the vein; and the enlargement of this small venous radicle produces the large stellated veins so commonly met with on the surface of diseased kidneys.

The venous branches which arise on the surface of the kidney, in the way just described, follow a straight course through the cortex, where they receive numerous tributary venous canals, and continue to increase in size till they form at last the large veins around the ureter. The distribution of the veins in the pyramidal masses of the kidney offers an interesting subject of contemplation to the anatomical inquirer. The capillaries surrounding the base of each pyramid unite into straight vessels, and these, again, are collected into bundles between the columns of tubuli : their direction being towards the mammillary process. In their progress they frequently divide and re-unite. At the apex of the mammillary process these vessels form a considerable plexus, the ramifications of which are often larger than the direct vessels which enter them, presenting occasionally, also, dilated receptacles. In their approach to this plexus, the straight vessels establish frequent intercommunications by means of large transverse branches; and, at intervals, between the base and apex of the pyramid, many of them form loops, and return on their course.

Continuous with the plexus there are besides vessels which take a retrograde course towards the base of the pyramid, where some of them enter the venous trunks, whilst others appear like prolongations of the venous radicles. These veins of the medullary region of the kidney are frequently

* Vide Mr. Kiernan's Researches on the Liver. Philosophical Transactions, 1833. 
found to be highly charged with blood. On reviewing the mode of arrangement of the venous branches, which has just been described, it will be evident that, on the external and internal surface of the organ, they constitute receptacles for blood of no inconsiderable capacity. It would seem but reasonable, therefore, to infer that, under certain conditions of the circulation in the kidney, the venous plexuses on the surface of the organ, together with those in its pyramidal masses, ought to be regarded as receptacles for the venous blood, precisely in the same way as, under like conditions, the Malpighian corpora are for the arterial.

\section{Pathological Observations.}

Previous to stating the result of my own investigations into the pathology of Bright's disease, I am desirous of making a few observations on the recent researches of which it has been the subject, more especially in this country.

There appears to be no doubt that the true cause of this disease is the circulation in the blood of the organ, of an unnaturally large quantity of carbonized and azotized elements. The condition may exist in two widely different cases.

1st.-Among the richer classes of this country, where the mass of the blood may become supercarbonized in connection with a full habit of body, food too nutritious, and deficiency of exercise.

2nd.-Among the working classes, from want of sufficient oxygen in the air of their close and ill-ventilated abodes, to decarbonize the blood in the lungs, and the constant use of fermented and spirituous liquors.

It has been proved that the ultimate effect of this supercarbonized state of the blood, is the deposition, in the kidney, of adipose matter. In the words of Dr. Johnson, "Bright's disease may be described as primarily and essentially an ex- 
aggeration of the fat which exists naturally in small quantities in the epithelial cells of the healthy gland."

Many observers in this and other countries have noticed the presence of an unusual quantity of fat in the kidney as characteristic of Bright's disease; and among my own notes there are drawings, made four or five years ago, of the oily globules found in the tubuli. But these and all other researches on this point must now be considered as supplementary to, and confirmatory of, the view advanced by Dr. Johnson in his elaborate and comprehensive paper, read during the present session, and which appears to me to be the only account which exhibits the disease in its true relations.

In the observations which will presently be submitted, I have divided the disease into three stages, each of which is founded on certain pathological conditions of the organ ; but antecedent to the development of the phenomena peculiar to any of these changes, there are grounds for believing that the organ is for some time in a state of congestion.

Dr. George Robinson,* in his very interesting and valuable contribution towards a knowledge of this disease, has clearly shown that a congested state of the blood-vessels of the kidney gives rise to albuminous urine; and he concurs with Dr. Bright, and many other observers, in thinking that this condition precedes the other stages of the disease. From this conclusion Dr. Johnson differs, for he states, "There is no reason for believing in the existence of any congestive stage as necessarily preceding any morbid change." Now, considering that in this disease the blood is highly charged with carbonized principles, and, consequently, that in its circulation through the kidney, that organ must be called upon to throw off a larger quantity of carbonaceous matter than the natural secretion would contain, an amount of irritation will be excited which must be followed by nervous depression and ultimate congestion of the entire organ. This general view, combined with the results of my investigations into the early

* Med.-Chir. Trans. vol. xxvi. 
stages of the disease, induces me to agree with Dr. Bright, and others, that the congestive condition of the blood-vessels of the organ does precede, and that necessarily, the deposition of fat, the enlargement of the organ itself, or of its uriniferous tubes, or of any other of its vessels.

The cause of the presence of albumen in the urine is acknowledged to be an obstructed condition of the blood-vessels of the organ. Dr. Johnson considers the obstruction to arise from a deposition of fat in the tubuli uriniferi; but there can be no doubt that albuminous urine often exists without any such deposition.

The first stage of the disease.-In this stage, the kidney is enlarged, and innumerable black points are visible, which are the corpora Malpighiana dilated, and their vessels distended with blood, seen through the capsule. The white spots, which derive their appearance from the collection of fatty matter, begin to be perceptible.

The peculiar features of this stage consist of an enlargement of the arteries entering the corpora Malpighiana; the dilatation of the vessels of the tuft, the capillaries and the veins; an increase in the size of the capsule of the corpus and of the tubuli, and a large addition to the quantity of the parenchyma of the organ.

The condition of the arteries is visibly changed, even at this early period: the artery entering the corpus being actually twice or thrice its natural size, which is the case also with the Malpighian tuft and the capillary vessels which spring from the tuft. An injection, in this stage, cannot very easily be made to pass through the tuft and fill the capsule of the corpus, - a circumstance which almost always attends injection in the later stages of the disease.-(Plate IX. fig. 2.)

The capillaries and veins are greatly enlarged, giving to the surface of the organ the resemblance of network.-(Plate X. figs. 2 and 3.) This is the commencement of the stellated condition, which is so marked a characteristic of the next stage of the complaint. 
The tubuli in this stage are also much increased in their dimensions ; but the fat which is found in them is soft and white.

The second stage of the disease.-The organ in this stage is very greatly increased in size, its surface is smooth, and presents numerous white spots; the capsule is but slightly adherent to the surface, and the tissue of the organ is flabby.

The structural changes exhibited during this stage are the following:-

1st.-The artery of the corpus Malpighianum becomes so greatly enlarged, that frequently it equals the dimensions of the tube itself, and is eight or ten times its natural size. It is tortuous and dilated, and sometimes, previous to entering the capsule of the corpus, presents analogous swellings to those of varicose veins. The primary branches of it, in forming the tuft, are also distended to ten or fifteen times their natural size, and are not unfrequently discovered external to the capsule of the corpus, as though thrust out by some internal force. The vessels forming the tuft are likewise enormously enlarged, and very often the minutest branches are fully as large as the main artery of the corpus in a healthy state.

Occasionally the tuft is broken up, and instead of forming a compact mass, exhibits its individual branches separated from each other. At other times the branches of the tuft are actually larger than the primitive artery of the corpus.(Plate IX. figs. 3 and 4, and Plate XI. fig. 2.) Under these circumstances it is singular that Mr. Bowman should have made the following remarks:- "Though I have examined, with great care, many kidneys at this stage of the complaint, I have never seen, in any one instance, a clearly dilated condition of the Malpighian tuft of vessels." He adds, "On the contrary, my friend Mr. Busk, an excellent observer, has specimens which undoubtedly prove these tufts not to be dilated in the present stage ; and I possess injected specimens showing them at all vol. $\mathbf{X X I X}$. 
stages, but never above their natural size." It is very possible that the peculiar injection used by Mr. Bowman may account for the fact which he mentions, and this conjecture is rendered extremely probable, as in the latter stages of the disease the Malpighian tuft becomes pressed upon by the adipose accumulation within, and, after undergoing compression, will permit the fluid used in the process of double injection to pass through rather than yield and distend. There are instances again in which the tufts are not enlarged, but appear healthy even in organs otherwise extensively diseased: but it is important to add, that these tufts, both in the second and third stages, when but slightly enlarged, or even not enlarged at all, will offer free passage to the injection, on the most gentle pressure, without even distending the whole of their vessels, and thus indicate their diseased condition.

An enlargement of the renal arteries and dilatation of their branches are also observable in this stage of the disorder.

The capsule of the corpus, too, is in this stage very greatly increased in size, and during the process of injection becomes frequently filled with the injection thrown into the arterial system. Although thus enlarged, it does not become ovoid, but presents slight bulgings in several parts.-(Plate IX. figs. 3 and 4.)

The tubuli difier considerably from their healthy condition, being enlarged to two or three times their natural size, and aggregated together in masses, so as to lie in contact with each other, and form definite, roundish bodies : they are also extremely convoluted with numerous dilatations; frequently they are varicose.-(Plate IX. figs. 3 and 4.) At other times they present distinct aneurismal sacs, which bulge out from one part of the wall of the tube, to which they are attached by a small neck or pedicle.-(Plate VIII. figs. 14 and 15.) Occasionally, some of the vessels of a convolution are smaller than the others, and their size nearly natural. The tubuli in the masses are so closely packed, that the blood-vessels are evidently compressed, and rendered incapable of admitting an injuction. At times a tube even 
at some distance from the corpus, becomes very convoluted, and knotted into a mass.

Parenchyma.-In cases where the kidney is much enlarged, the parenchymatous cells will be found not merely increased in size, but adipose depositions will be visible throughout them.

The third stage of the disease.-The kidneys are smaller than their natural size; hard, white granules are prominent on their surface, which is more or less lobulated ; the capsule is adherent; vesicles of large size are frequently everywhere interspersed; and numbers of smaller ones stud the whole surface. On making a section, the organ is found to be deprived of blood; the cortical part contracted, the bloodvessels large, and their walls thick.

Arteries.-'The arteries are in a more contracted condition than that described in the second stage; and the Malpighian tuft is so often changed from its natural state, that the greater part of its vessels are not capable of being injected.

The capsule of the corpus has assumed a more contracted appearance.

The arteries in this stage are so difficult to inject, that some anatomists have denied the possibility of the operation. The difficulty has its origin in the great pressure, which is exerted on the whole of the arterial system, by the contraction and hardening of the organ.

Veins.-The veins in this stage present on the surface of the organ the well-known stellated aspect which arises from the gradual pressure exerted on the trunks, and the contraction of the organ. These changes are well delineated in the engraving.-(Plate $X$. figs. 4 and 5.)

Tubuli.-The tubuli are larger than in the preceding stage, and are gathered into rounded masses, which form the granules on the surface of the organ. The latter are of a white hue, and are most commonly fully distended with fatty depositions; though not unfrequently they appear like dark spots : the tubuli in that case being full of blood. A rounded 
appearance is generally characteristic of the granules, in each of which the component tubule forms innumerable convolutions. It is extremely difficult to inject the tubuli from the ureter ; indeed it is very rarely that it is possible to distend them from this source; nor is it an easy matter to fill them from the artery, though, as will be seen in the drawings, my efforts have not been without success. The tubuli are filled will oily cells, granular matter, particles of various sizes, and blood globules. Plate XI. figs. 1, 3, 4 and 5, illustrate the condition of the tubuli in the third stage.

Parenchyma.-The parenchyma is hard, and is composed of elongated stellated cells, from the angles of which fine threads proceed, and communicate with each other.

The nature and causes of the disease which has been under consideration, having now been tolerably well ascertained, professional duty demands the further very interesting enquiry, whether means can be adopted by which the development of the disease may be prevented.

Among all classes the use of a less stimulating diet,whether the stimulus arises from the excess of nutritious solids, as in the upper classes,-or from improper food and the abuse of intoxicating beverages, as in the working classes,-is one of the remedies whose obviousness renders all reasoning superfluous.

Vigorous and' regular exercise in pure air, and daily ablutions of the entire body, as promoting digestion and secretion, increasing the respiratory efforts to decarbonize the blood by the lungs, and the transpiratory excretions of the skin, will also be most valuable auxiliaries.

But among numerous bodies of the population, and especially among the labouring classes, other causes demanding other remedies would appear to be in operation. Dwellings badly built and drained, situated in close, confined and densely-populated localities, deprived of light, and constantly containing an impure air, exercise a very deteriorating influence on the physical condition of a large proportion of the 

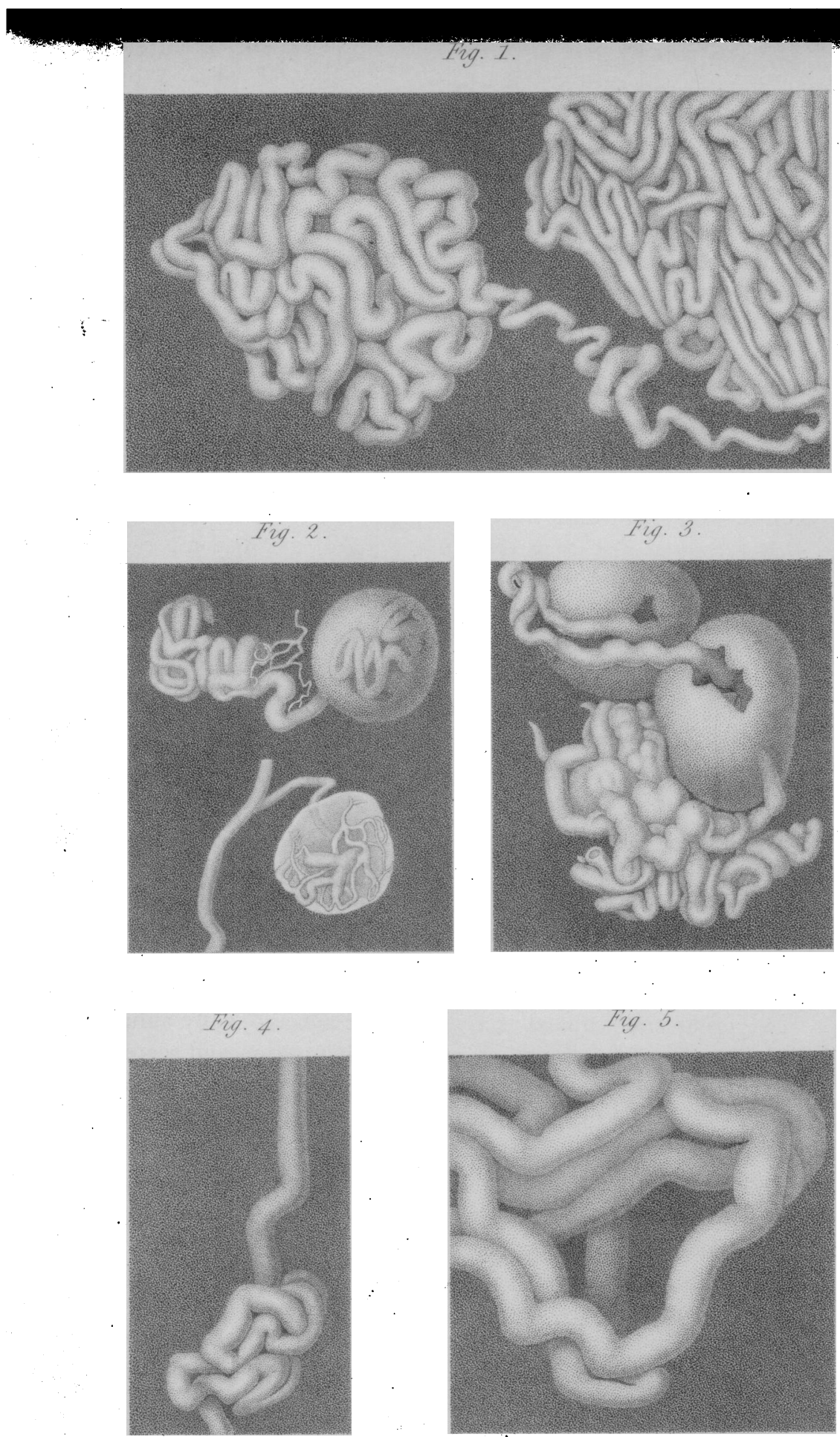
OF THE HUMAN KIDNEY.

industrious classes, and they are especially active in the production of the disease, which has formed the subject of this paper.

\section{EXPLANATION OF THE PLATES.}

\section{Plate VII.}

Figs. 1 and 2.-Portions of the cortical and pyramidal divisions of the kidney, the tubuli being distended from the ureter to the surface of the organ. Fig. 1, represents the periphery of the pyramidal mass. Fig. 2, the central part.

Figs. 3, 4, and 5.-Portions of the cortical part of the kidney, showing the arrangement of the tubuli.

Figs. 6, 7, 8, 9, 10, and 11.-Diagrams illustrating various modes in which the tubuli are disposed.

\section{Plate VIII.}

Figs. 1, 2, and 3.-Portions of the surface of the kidney, showing the mode in which the tubuli are arranged.

Fig. 4.-Capillaries ramifying over the tubuli on the surface of the kidney.

Fig. 5.-Tubuli passing from the cortical part of the kidney to the surface.

Fig. 6.-Capillaries ramifying over the tubuli in the cortical portion of the kidney.

Figs. 7, 8, and 9.-Diagrams of the tubuli.

Figs. 10, 11, 12, and 13.-Diagrams of the corpora Malpighiana.

Figs. 14 and 15. - Varicose conditions of diseased tubuli uriniferi. 


\section{Plate IX.}

Fig. 1.-The vascular plexus of the Malpighian body in a healthy state.

Fig. 2.-The vascular plexus enlarged, and its component vessels dilated.

Figs. 3 and 4.-The vascular plexus still further enlarged and diseased, the capsule much dilated, and the tubuli thrown into convoluted masses.

Fig. 5.-The capillary vessels on the surface of a kidney, in the early granulated state; they are extremely numerous and much enlarged, as is seen by a comparison with fig. 4, Plate VIII.

Fig. 6.-The capillary vessels on the surface of the kidney, in a later state of granulation, when there is great difficulty in injecting any of the blood-vessels.

\section{Plate X.}

Fig. 1.-The veins on the surface of a healthy kidney.

Figs. 2, 3, and 4.-The veins in the earlier stages of Bright's disease.

Fig. 5.-The stellated condition of vein in the advanced stages of the disease.

\section{Plate XI.}

Fig. 1.-Two granulations on the surface of the kidney in an advanced stage of Bright's disease.

Fig. 2.-Diseased blood-vessels in the interior of the Malpighian capsule.

Fig. 3.-Tortuous and varicose tubuli uriniferi.

Fig. 4.-A tube much enlarged, and forming a granulation in its passage through the cortical part of the organ.

Fig. 5.-A tube very much dilated.

In conducting the researches from which all of the above engravings were taken, Powell's $\frac{1}{2}$-inch object glass was used, the magnifying power of which is about 80 diameters. 